NBER WORKING PAPER SERIES

\title{
PRICE INDEXES FOR MICROSOFT'S \\ PERSONAL COMPUTER SOFTWARE PRODUCTS
}

\author{
Jaison R. Abel \\ Ernst R. Berndt \\ Alan G. White \\ Working Paper 9966 \\ http://www.nber.org/papers/w9966 \\ NATIONAL BUREAU OF ECONOMIC RESEARCH \\ 1050 Massachusetts Avenue \\ Cambridge, MA 02138 \\ September 2003
}

This research was originally sponsored by Microsoft Corporation in the context of various antitrust allegations, and was conducted under the direction of Ernst Berndt. The opinions expressed herein are those of the authors and not necessarily those of Microsoft Corporation, its legal counsel, MIT or the NBER. The authors gratefully acknowledge the assistance and input of many on this project -- in particular, Cory Monroe, Sarita Digumarti and Eric Korman for numerous hours of careful and thorough research assistance, other staff at Analysis Group, and Microsoft counsel for helpful comments and suggestions. The views expressed herein are those of the authors and not necessarily those of the National Bureau of Economic Research.

(C)2003 by Jaison R. Abel, Ernst R. Berndt, and Alan G. White. All rights reserved. Short sections of text, not to exceed two paragraphs, may be quoted without explicit permission provided that full credit, including (C) notice, is given to the source. 
Price Indexes for Microsoft's Personal Computer Software Products

Jaison R. Abel, Ernst R. Berndt, and Alan G. White

NBER Working Paper No. 9966

September 2003

JEL No. D4, E3, L86

\section{$\underline{\text { ABSTRACT }}$}

Using a unique and comprehensive data source, we measure price changes for Microsoft's desktop personal computer software products during the time period July 1993 through June 2001. This paper contributes to a relatively small literature on price measurement of pre-packaged software by incorporating important channels of distribution, such as volume licensing and Original Equipment Manufacturer, as well as changes in product form, such as upgrades and integrated productivity suites, into matched-model price indexes. Although there are differences over time periods and across products, we find that the prices of Microsoft's desktop operating systems and applications have generally been falling over this time period.

Jaison R. Abel

Analysis Group

Boston, MA

jabel@analysisgroup.com

Ernst R. Berndt

Sloan School of Management

Massachusetts Institute of Technology

50 Memorial Drive

Cambridge, MA 02141-1347

and NBER

eberndt@mit.edu

Alan G. White

Analysis Group

Boston, MA

awhite@analysisgroup.com 


\section{Introduction}

In this paper, we report on research examining measures of price changes for Microsoft's personal computer software products over the time period July 1993 through June 2001. The focus of this paper is on the measurement of price changes for Microsoft's software products, not on the factors underlying or causing any price changes. As such, this paper adds to a relatively small literature on price indexes for PC software products (summarized in Section VI of this paper). That literature for the most part ends in 1994 or earlier, and typically focuses on sales only in the retail or mail order channels, for full versions of software products. We argue below that changes in product form and distribution channel since 1994 imply that retail/mail order sales of full versions of stand-alone software products are increasingly unrepresentative of Microsoft's transactions. We therefore examine price changes for Microsoft's software products based on prices received by Microsoft for virtually all its PC software products over the primary channels of distribution through which Microsoft sells.

More specifically, here we report on the measurement of price changes in Microsoft's PC desktop operating systems and applications over the time period July 1993 through June 2001. The operating systems included in this analysis are MS-DOS, Windows, Windows 95, Windows 98, Windows Millennium Edition, Windows NT Workstation, and Windows 2000 Professional. In terms of applications, we measure price changes for the applications Word and Excel (sold as stand-alone products and in suites such as Office and Works), and Office. ${ }^{2}$ We collectively refer to these Microsoft operating systems and applications products as "the Microsoft Products".

\section{Background: Significant Changes in the Marketplace for Prepackaged PC Software}

Summarizing the pricing behavior of a large multiproduct firm is particularly challenging when diverse product market segments are dynamic, and significant changes occur over time involving channel of distribution mix, product form, and quality improvements. This is clearly the case in the markets for prepackaged PC software that we study. For Microsoft's operating systems, between 1993 and 2001, the majority of licenses were sold through the Original

\footnotetext{
2 A "stand-alone" version of software is one that is not sold as part of a suite or any other integrated software package.
} 
Equipment Manufacturer (OEM) channel $^{3}$, while full packaged product (i.e., in a shrink-wrapped package) sales declined significantly from 1995 (when Windows 95 was introduced) to 2001. For applications, the share of licenses sold under volume-licensing agreements increased substantially during the 1993 to 2001 time period. ${ }^{4}$ In fact, volume licensing sales have largely replaced the shrink-wrapped full packaged product sales of the early 1990s. Finally, sales of applications software have grown more rapidly than those of operating systems, with the license share of applications growing from about 20 percent in 1993 to slightly more than a third of sales in 2001.

Changes in the product form have also occurred over time for both applications and operating systems. At various times upgrades to pre-existing software versions have comprised a significant percentage of sales, depending on the timing and release of new versions of various operating systems (e.g., Windows 95) and applications. For applications, Enterprise Agreements (described below) have constituted an increasing percentage of applications sales - over 25 percent of applications sales in 2001. There has also been a dramatic shift in product form for Word and Excel during the 1990s with sales of Word/Excel as part of the Office suite almost completely replacing stand-alone sales of Word and Excel. For example, for Excel, in 1993 the proportion of licenses sold in stand-alone form was about 35 percent while the remaining approximately 65 percent of licenses were sold as part of the Office suite; by 2001, these proportions had changed to less than 1 percent and over 99 percent respectively. For Word, the stand-alone share has fallen from about 50 percent in 1993 to less than 10 percent in 2001.

Prices for Microsoft's software differ considerably across channel, user type and product form, so that changing compositions have a material impact on aggregate average price or price index calculations. Such changes need to be accounted for in measuring aggregate price trends over time. For example, the average prices for operating systems sold through the OEM channel

Sales in the OEM channel are primarily to personal computer manufacturers, such as Compaq and Dell. Sales in the finished goods channel are primarily to distributors and resellers.

4 In these calculations, a suite such as Office is a single license, even if it contains both word processor (Word) and spreadsheet (Excel) components. Volume licensing programs are pricing agreements targeted toward larger organizations that provide discounts based on the number of desktops for which Microsoft software is licensed. Open and Select agreements are two of Microsoft's most popular volume licensing programs. 
are generally lower than those in the finished goods channel. An overall average price across both channels of distribution would lie somewhere in between the two average prices from the separate channels, depending on the relative sales and price level differences between these two channels of distribution.

Economists have long recognized that in such a dynamically evolving context, in order to measure aggregate price change, the use of chain-weighted price index procedures is generally preferable to various average price calculations. However, it is also widely believed that use of price index methods, such as the chained matched-model methods, can fail to incorporate fully the quality change implications of exiting and newly entering goods; see, for example, discussions in Oliner and Sichel (1994) and Grimm and Parker (2000). Indeed, as discussed below, this failure to capture fully the quality-adjusted price declines has led the Bureau of Economic Analysis (BEA) to make an explicit additional quality-adjustment when constructing and utilizing the Bureau of Labor Statistics' (BLS') prepackaged software PPIs in computing real GDP by industry.

\section{Elementary Units and Aggregate Price Indexes}

\section{Elementary Units and Matched-model Price Indexes}

In the matched-model framework of price index measurement, a well-defined product, called an elementary unit, is identified on the basis of the product's distinct price-determining characteristics. It is this elementary "matched-model" unit that is used as the basic building block for making price comparisons over extended time periods. Price changes of elementary units are then weighted to construct aggregate price indexes. In particular, when the BLS collects price data for its monthly price indexes, an effort is made, wherever possible, to compare prices of the same well-defined elementary units over time. By defining the elementary unit in detailed terms, and then comparing prices over time only for well-defined matched-models, the price index comparison avoids problems caused by comparing prices of different products. Although matched-model price indexes have some limitations (such as the inability to capture

fully quality change effects from newly entering or exiting products), currently, in almost all developed countries, measures of aggregate price inflation are constructed by government statistical agencies using matched-model procedures. 


\section{Fixed Basket Indexes, Laspeyres, Paasche and Fisher}

The fixed basket approach to measuring price changes is used by the BLS and implicitly by the BEA. By a fixed basket, it is meant that price changes of a fixed set of clearly defined elementary units are compared over time. The weights that are applied to this fixed set of elementary units to calculate an aggregate price index are also fixed over time. In practice, the implementation of a fixed basket price index raises a number of difficult issues. Products disappear and new products appear over time. When this occurs, the fixed basket can become unrepresentative or even obsolete. Furthermore, as prices of certain products become relatively more expensive, the fixed basket approach does not take into account the fact that some consumers will switch to products that are relatively less expensive (which implies that the quantities and quantity weights associated with the relatively more expensive products would become smaller).

Not only does the fixed basket approach assume fixed quantities of the products whose prices are being measured over time, but in general it also implicitly assumes that the quality of these products is held constant. For many products, product quality has improved over time, and this quality change needs to be taken into account when computing quality-adjusted measures of price change. Over the years, the problems of unrepresentative baskets, exiting and new products, and quality change have been discussed in numerous reports and studies, most recently by the Boskin Commission, The Conference Board, and the National Academy of Sciences, all with respect to the U.S. Consumer Price Index (CPI) published by the BLS. ${ }^{5}$

Much of index number theory and the academic literature on price indexes focuses on the issue of which index number formula is most appropriate when combining prices of varying products over time into a summary measure of average changes in prices. One characteristic that

\footnotetext{
Boskin, M. J., Dulberger, E. R., Gordon, R. J., Griliches, Z. and Jorgenson, D. W. (1996), Toward a More Accurate Measure of the Cost of Living, Final Report to the U.S. Senate Finance Committee from the Advisory Commission to Study the Consumer Price Index; The Conference Board (1999), Measuring Prices in a Dynamic Economy: ReExamining the CPI, New York; and National Academy of Sciences (2002), At What Price? Conceptualizing and Measuring the Cost-of-Living and Price Indexes, Panel on Conceptual, Measurement and Other Statistical Issues in Developing Cost-of-Living Indexes, C. Schultze and C. Mackie, eds., Committee on National Statistics, National Research Council.
} 
distinguishes different price index number formulae is the choice of weights that are applied to the different prices. Some indexes weight all prices equally (called "unweighted" indexes) while others use distinct and unequal weights for different products (called "weighted" indexes). ${ }^{6}$ The best-known weighted index number formulae used for making price comparisons over time are the Laspeyres, Paasche, and Fisher price indexes.

The BEA computes its price indexes using a variant of the chained Fisher Ideal price indexes; these official price indexes are used when the BEA converts nominal gross domestic product (GDP) and nominal gross product by industry (GPI) into inflation-adjusted real GDP and real GPI. ${ }^{7}$ In this paper, measures of price change in the Microsoft Products over time are constructed based on the chained Fisher Ideal price index, using sequentially updated quantity weights. We also present the Laspeyres and Paasche versions of the price indexes.

Laspeyres and Paasche price indexes can differ considerably in situations where weights are changing rapidly. When demand curves are fixed, it is of course well-known that in response to a small increase in the price of one good, the measured price increase will be larger for the Laspeyres than the Paasche price index. When demand curves are shifting, however, this need not be the case. On the supply side, firms can increase quantity supplied in response to a price increase, generating a situation in which the measured price increase will be larger for the Paasche instead of the Laspeyres. More generally, the following relationship can be shown to exist between the Laspeyres and Paasche price indexes, when computed over bilateral time periods:

$$
\frac{P_{P}}{P_{L}}=\frac{Q_{P}}{Q_{L}}=1+r\left(\frac{\sigma_{p}}{P_{L}} \frac{\sigma_{q}}{Q_{L}}\right)
$$

A discussion of differences in weighting methodologies in prices indexes can be found in Diewert, W. E. (1995), 'Axiomatic and Economic Approaches to Elementary Price Indexes,' Discussion Paper No. 95-01, University of British Columbia; and Balk, B. E. (1995), ‘Axiomatic Price Index Theory: A Survey,' International Statistical Review 63, 6993. 
where $P_{i}, Q_{i}, i=L, P$ are the Laspeyres $(L)$ and Paasche $(P)$ price and quantity indexes respectively, $r$ is the weighted correlation coefficient between the price and quantity relatives, and $\sigma_{i}, i=p, q$, are the weighted standard deviations of the price and quantity relatives respectively. Note that the expression in parentheses in equation (1) is the product of two coefficients of variation, i.e., the standard deviations of the price and quantity relatives divided by their respective weighted means. Since the product of the two terms in parentheses is always positive (assuming a non-zero standard deviation), the sign of $r$ is sufficient to determine the direction of the divergence between the Paasche and Laspeyres price indexes, e.g., if $r$ is positive (negative) then the Paasche price index value will be greater (less) than the Laspeyres price index value calculated over the same time period. A derivation of this formula can be found in Allen (1975, pp. 62-63), drawing on earlier work by von Bortkiewicz (1922, 1924, referenced in Allen (1975)).

Although relatively uncommon, there are instances in the published literature in which the Paasche price index shows a greater increase or a smaller decline than the Laspeyres price index. In Berndt, Busch and Frank (2001, Table 12.7, p. 491), for example, between 1991 and 1992, a Laspeyres price index for the treatment of acute phase major depression increased from 1.000 to 1.003 , while the Paasche increased from 1.000 to 1.011. The intuition behind this is that non-homothetic demand shifts were occurring that were larger for the increasingly expensive component treatments. In that context, as physicians learned about the efficacy and increased tolerability of a new class of higher priced antidepressant drugs (a class known as the selective serotonin reuptake inhibitors), relative demand shifts occurred favoring the higher priced treatment. A related interpretation is that the measured prices in that context failed to account properly for quality improvements in the new class of antidepressant drugs, and that had proper quality-adjusted prices been utilized instead, the more common Paasche less than Laspeyres price increase result might instead have resulted. Allen (1975) discusses other contexts in which various inequalities between Paasche and Laspeyres can occur; a related discussion is also found

The BEA uses price indexes published by the BLS, and occasionally modifies these, and then uses these as inputs when constructing measures of real output. For an account of BEA's adoption of the Fisher price index, see Triplett, J. E. (1992), 'Economic Theory of BEA's Alternative Quantity and Price Indexes,' Survey of Current Business 72, 49-52. 
in Danzon (2000). Since observed price and quantity movements reflect the net outcome of changes in demand and supply, differing inequalities between measured Paasche and Laspeyres price index changes can occur over time reflecting a variety of underlying shifts in demand and supply.

Below we present empirical findings on the divergence between Laspeyres and Paasche price indexes in the context of software price indexes for the Microsoft Products, and put forward interpretations of these divergences. We note in passing that substantial differences between Paasche and Laspeyres price indexes have been reported by Prud'homme and $\mathrm{Yu}$ (2002) based on matched-model price indexes and scanner data for various prepackaged PC software products sold in Canada between January 1996 and June 2000. Notwithstanding these inequalities in the two components of the Fisher Ideal price index, we emphasize that the literature expresses a strong desire for using the Fisher Ideal price index for measuring price changes over time (see in particular Diewert (1992)).

\section{Matched-model Price Indexes for Microsoft's Software Products}

\section{Data}

We now consider implementation of the chained Fisher matched-model price index method to measure price changes for the Microsoft Products. The data we use for our analyses are from MS Sales, Microsoft's internal transactions database, and cover the time period July 1993 through June 2001. ${ }^{8}$ These data contain revenue and license information for the universe of Microsoft's sales into the first line of distribution, e.g., distributors and OEMs. Producer prices and corresponding weights are calculated from these data, and are then used in the matchedmodel price indexes reported below. Since the transactions prices reflect prices received by Microsoft at the first point in the distribution chain, they are best interpreted as corresponding to producer rather than consumer price indexes.

Specifically, the data used in our analyses are taken from the Microsoft "As Shipped" and "As Allocated" perspectives of the MS Sales data. 
The products contained in the MS Sales data are organized in an hierarchical fashion at different levels of aggregation. The product family level of the MS Sales product hierarchy provides the most appropriate grouping of transactions for the purposes of constructing matchedmodel indexes for the Microsoft Products. ${ }^{9}$

\section{Identifying the Elementary Unit}

Defining the elementary unit for making price comparisons is the first step in constructing matched-model price indexes. We employ two considerations in drawing the boundaries of an elementary unit, i.e., in defining "buckets" of distinct elementary units. We placed two products in the same bucket only if two conditions were satisfied. First, we placed two products in the same bucket if substitutability in response to a price change would likely be substantial, but placed them in separate buckets if possibilities for substitutability in response to a price change were likely to be very limited. Thus, because of the substantial costs of changing one's eligibility, academic sale products were placed in a bucket different from non-academic sales. Similarly, because eligibility to purchase an upgrade was contingent on first purchasing the full version, upgrades were treated as a separate elementary unit from full versions. A second criterion was based on functionality. Here the issue is what criteria to use in determining whether two versions of, say, a word processor program, were sufficiently similar or different to merit placing them in the same, or in different buckets. Software companies such as Microsoft typically release a new version of a product, e.g., moving from version 5.xx to 6.xx, after they have made significant changes to the product. Because new versions can contain significant changes to the original product and may be priced differently, new versions of a product are properly viewed as a separate product, i.e., as a distinct elementary unit within the context of the matched-model framework. It is also common for software companies to update their products, e.g., move from version 3.1 to version 3.2, to correct "bugs" in the source code or to introduce

\footnotetext{
Microsoft defines a product family as "A group of functionally equivalent products that share the same core features, facilities, and public name across multiple operating systems, versions, and languages." MS PRODUCT Attribute Reference Guide, p. 17, last updated October 19, 2001. The desktop operating systems product families used in our analyses are: "MS-DOS," "MS-DOS with Enhanced Tools," "Windows," "Windows for Workgroups," "Windows 95," “WIN95/ISK BUNDLE," "Windows 98," “Windows ME," “Windows NT Workstation," and "Windows 2000 Professional." The applications product families used in our analyses are: "Word," "Excel," "Office," "Office Professional," "Office Pro w/VisFoxPro," "Office Pro/Bookshelf Bundle," "Office w/Bookshelf," "Office Small
} 
minor changes to the previous product. Since such updates do not constitute significant changes in functionality, and typically are offered free to licensees having purchased that version, it is appropriate to treat them as part of the same elementary unit to which the previous version belongs.

Although these boundaries are inherently to some extent subjective, it is worth noting that in computing its producer price indexes for prepackaged software, the BLS generally treats different versions as distinct elementary units, e.g., version 5.xx as different from 6.xx, but treats updates as being in the same elementary unit as the original version. This construction of boundaries among versions and updates is also consistent with procedures utilized in Oliner and Sichel (1994), and in the maximum overlap method of Prud'homme and Yu (2002).

With these general considerations in mind, for the Microsoft Products we define elementary units along the following four dimensions:

- Channel:

- User Type:

- Academic Status:

- Product Family Version
Finished Goods, OEM

Full Version, Upgrade/Maintenance, Enterprise Agreement Academic, Non-Academic

E.g., Office Professional 6.XX

Defining an elementary unit in this way ensures that period-to-period price comparisons for a product are not influenced by underlying changes in product form or channel composition. For example, a product sold through the finished goods channel typically has a higher price level than the same product sold through the OEM channel. If prices within a channel remained constant as relatively more consumers purchased via the finished goods channel, then a periodto-period comparison of prices over both channels for this product would lead one to conclude erroneously that prices have increased. Therefore, when measuring price changes over time it is important to control for the channel through which the product is sold.

Business," "Office Pro/Bookshelf/Vfoxpro," “Office Premium," “Office Pro w/FrontPage," "Office Pro Special Edition," and "Office Pro w/Publisher." 
A similar issue exists regarding the user type and academic status of a product. The prices of products sold as a full version, upgrade/Maintenance, or as part of an Enterprise Agreement can differ quite substantially. The same is true of products sold to academic and nonacademic consumers. Thus, as with channel of distribution, it is necessary to control for the changing underlying composition of the academic status and user type to which the software is ultimately sold.

Maintenance agreements are arrangements typically entered into by volume licensing customers that provide a customer with all upgrades released for a given Microsoft product over a two-year time period. Thus, Maintenance agreement licenses are functionally equivalent to upgrades. In our analyses, Maintenance agreements have therefore been grouped in the same bucket as the more traditional upgrades. Enterprise Agreements, which Microsoft introduced in November 1997, are typically three-year agreements that provide volume discounts for a combination of full-version and upgrade products, and contain a built-in Maintenance component. ${ }^{10}$ Because they represent a combination of full versions and upgrades, we treat them as a distinct elementary unit.

Since Maintenance and Enterprise agreements are not traditional single-user licenses, several adjustments to our data analyses were necessary so that they could be incorporated into the price index calculations. Because Microsoft allows its customers to pay for the software they license over the life of each agreement, we developed a procedure based on historical software trends and lifecycles that capitalized the revenue associated with Maintenance and Enterprise Agreements in order to make the price comparable to more traditional software licensing programs. This was accomplished by doubling the revenue attributed to the Maintenance category (which is typically a two-year agreement) and tripling the revenue attributed to the Annuity (Enterprise Agreement) category (which is typically a three-year agreement) observed in a given year in which the original purchase occurred. In addition, since customers are entitled 
to automatic upgrades during the life of each agreement, we implemented a procedure based on historical software trends and lifecycles that adjusted the number of licenses a typical customer would realize over the course of each agreement. According to the U.S. BLS, the average product life cycle for a successful software product is 18 months. ${ }^{11}$ This suggests that, on average, a typical Maintenance agreement would be associated with 1.33 licenses over two years, while a typical Enterprise Agreement would be associated with 3 licenses over three years since a license is obtained at the beginning of the agreement. These "capitalized" revenue and "realized" licenses are then used to compute the per unit license prices for the elementary units involving Maintenance and Enterprise Agreements.

Once the elementary unit has been defined, one must then identify and obtain two fundamental pieces of information: prices and corresponding weights. Using data from MS Sales, we calculate the average price, by calendar year and product family version, along each of the eight dimensions below: ${ }^{12}$

- Finished Goods, Full Version, Non-Academic

- Finished Goods, Full Version, Academic

- Finished Goods, Upgrade/Maintenance, Non-Academic

- Finished Goods, Upgrade/Maintenance, Academic

- Finished Goods, Enterprise Agreement, Non-Academic

- Finished Goods, Enterprise Agreement, Academic

- OEM, Full Version, Non-Academic

- OEM, Upgrade/Maintenance, Non-Academic operating system, and Back Office (a server-based product), but currently Enterprise Agreements are offered separately for individual products as well.

11 Bureau of Labor Statistics (2000), Industry Synopsis, SIC 7372 Prepackaged Software, p. 17.

12 Maintenance and Enterprise Agreement transactions occur only in the finished goods channel. Within the OEM channel, only non-academic sales take place. 
Calculating prices on an annual basis allows for the effect of returns and credits to be incorporated into the analysis. In some instances, particularly in the context of monthly or quarterly periodicity, due to the incorporation of returns and credits, negative prices, revenues, and/or licenses may emerge for a particular elementary unit in a given year. When this situation arose in the annual context (which was considerably less frequent than with monthly or quarterly time intervals), in order to preserve the match we replaced the negative price with the most recent positive price from a previous time period and assigned this price a weight of zero.

\section{Results of Price Changes for Microsoft Products}

Prices for the Microsoft Products have in general declined between 1993 and 2001. The extent of price decline varies among products and across different time periods. Trends in aggregate matched-model price indexes for stand-alone Word, stand-alone Excel, Office, and desktop operating systems are displayed in Tables 1 and 2 below. ${ }^{13}$ Initially we discuss price index changes based on the Fisher Ideal price index, and later on we focus on differences between the Paasche and Laspeyres components of the Fisher Ideal.

As seen in Table 1, for stand-alone Word, the cumulative price index decline between July 1993 and June 2001 was 50.16 percent, reflecting an AAGR of -8.34 percent. ${ }^{14}$ For standalone Excel, the corresponding cumulative price decline was 9.12 percent, with an AAGR of 1.19 percent. For Office, the 1993 to 2001 cumulative price decline was 32.40 percent, or -4.78 percent per annum. For Microsoft's desktop operating systems, the cumulative price decline between 1993 and 2001 was 3.10 percent, or -0.39 percent per annum.

A major shift in product form for Word and Excel occurred during the 1990s. This shift involved a substitution of sales of stand-alone Word and stand-alone Excel into sales of the

\footnotetext{
13 Typical numbers of matches for these matched-model indexes range from 9 (for stand-alone Excel) to 93 (all Microsoft Products), depending on the product index and year.

14 For a price series starting in year 0 and ending in year $n$, we compute $A A G R=\left(\mathrm{P}_{n} / \mathrm{P}_{0}\right)^{1 / n}-1$. Although we only have six months of data for both 1993 and 2001, for purposes of computing an AAGR we treat these as full years so that the 1993 to 2001 time period represents nine full years.
} 
integrated Office and Works suites. Both stand-alone and suite product forms of these products were simultaneously available during the entire 1993 to 2001 period.

Each license of Office can be considered as consisting of, among other programs, a license for Word and a license for Excel. The shift from stand-alone Word and Excel to the Office suite resulted in an effective price decrease to purchasers of Microsoft software. Consider, for example, the following hypothetical example involving the average prices of full versions of the full packaged product versions of Excel and Word, and of the Office Standard suite. Assume that customers purchasing both stand-alone Word and stand-alone Excel separately pay on average a total of $\$ 200$ ( $\$ 100$ for Word and $\$ 100$ for Excel); assume that the average full packaged product price of the Office Standard (containing not only Word and Excel, but also other software products such as PowerPoint and Outlook) is $\$ 150$. By purchasing the integrated Office Standard suite instead of stand-alone versions of Excel and Word, the effective price charged by Microsoft is lowered by at least 25 percent (i.e., from $\$ 200$ to $\$ 150$ ). ${ }^{15}$

One way of assessing the magnitude of the overall effective price reduction for Word and Excel attributable to the shift to the Office suite is to allocate a portion of Microsoft's Office revenues to Word and Excel, and then to compute new effective Word and Excel prices each averaged over their stand-alone plus allocated sales. ${ }^{16}$ Using Microsoft's internal allocations, we compute All Word and All Excel price indexes aggregated over stand-alone and allocated Office and Works sales. As shown in Table 2, the cumulative price decline for All Word was 59.34 percent, or -10.64 percent per annum. The cumulative decline in the price of All Excel between 1993 and 2001 was 49.44 percent, or -8.17 percent per annum. These 1993 to 2001 cumulative price declines for All Word and All Excel were larger than those for stand-alone sales, i.e., 59.34 percent compared to -50.16 for Word, and -49.44 percent compared to -9.12 percent for Excel.

\footnotetext{
15 This 25 percent price decline does not account for additional products included in the suite, such as PowerPoint and Outlook.

16 Since Word is also sold as part of the Works Suite, an allocation from Works must also be made. To identify the version of Word and Excel sold as components of particular Office and Works suites, we used information from
} 
Finally, aggregated over all the Microsoft Products, the 1993 to 2001 cumulative price change was -29.43 percent, reflecting an AAGR of -4.26 percent (Table 2). ${ }^{17}$ We have also performed a number of sensitivity analyses on our results by looking at different configurations of the elementary unit. For example, we have treated stand-alone and "allocated" as separate products (elementary units), and computed price indexes at the product unit level (a higher level of aggregation than the product family level, in which the various versions of, say, Word, are placed in the same elementary unit). When stand-alone and allocated Word are treated as separate elementary units the All Word price index declines at an annual rate of 8.38, compared to an annual decline of 10.64 percent per year when they are combined into one elementary unit. When the Microsoft Products price index is computed at the product unit level it declines at a rate of 2.16 percent per annum, compared to a decline of 4.26 percent per annum when the elementary unit is defined at the product family level.

In the context of a constant utility framework with stationary preferences, a well-known result is that the Paasche price index rises less rapidly (or declines more rapidly) than the Laspeyres price index (see Diewert (1993)). As shown in equation 1 above, the Paasche price index value may be higher than that of the Laspeyres price index value when the correlation coefficient between the bilateral price and quantity relatives is positive. To interpret our occasional finding of a slower price decline in the Paasche relative to the Laspeyres, in Table 3 we present such annual correlation coefficients for the price and quantity relatives of operating systems and various applications, and for Microsoft products in aggregate.

In order to preserve matches in the index calculations we replaced any negative price with the most recent positive price from a previous time period and assigned this price a quantity weight of zero. Because of this method, the calculations of the correlation coefficient and the Laspeyres and Paasche price indexes are based on different numbers of observations (when, for

Microsoft's “As Shipped” data. We then allocated suite revenues to the various versions of Word and Excel, using Microsoft's internal allocations.

17 The Microsoft Products price index is calculated by combining price changes for All Word, All Excel, and desktop operating systems. 
example, the quantity is set to zero, resulting in an undefined quantity relative). For this reason it may not be possible to verify the von Bortkiewicz decomposition for every period and every product -- in fact the relationship does not hold for 24 of the 56 bilateral comparisons in this paper (e.g., for stand-alone Word for 1995-1996 and for 1997-1998). Notwithstanding this, for stand-alone Word, stand-alone Excel, Office, and Microsoft Products in aggregate, in five of the eight years the correlation coefficient is negative, while for All Word (All Excel) it is negative in six (seven) of the eight years, suggesting the familiar inequality of the Laspeyres declining less than the Paasche. For operating systems, however, a positive correlation between bilateral price and quantity relatives occurs in five of eight years, and the Laspeyres price index declines more than the Paasche.

Over the eight year time span, the average correlation coefficient between bilateral price and quantity relatives for operating systems is positive. As is seen in Figure 1, this results in a Paasche price index having a cumulative price change of 4.12 percent, a Laspeyres price index having a smaller cumulative price change of -9.82 percent, and the Fisher Ideal having a cumulative price change in between at -3.10 percent. In a price index study of software based on Canadian scanner data transactions between 1996 and 2000, Prud'homme and Yu (2002) report very different growth rates based on the various price indexes; their AAGRs are $\quad-24.9$ percent with the Paasche, 18.0 percent with the Laspeyres, and -5.9 percent with the Fisher Ideal.

One interpretation of the positive correlations between price and quantity relatives occasionally found in the Microsoft data, particularly in the context of operating systems, is that they reflect the positive feedback on sales from network externalities. A related interpretation is that measured prices do not properly control for quality aspects such as network externalities. ${ }^{18}$ An analysis of quality-adjusted prices for software is not undertaken in this paper, though future work may investigate this issue. 


\section{Existing Research on Measuring Prepackaged Software Prices}

\section{Studies on Software Price Changes}

There have been relatively few research studies to date that report estimates of measures of prepackaged software price changes over time. In addition, the only studies of which we are aware that have reported price indexes for a multi-product firm operating in an unregulated price context are those by Cocks $(1974,1977)$ for a pharmaceutical manufacturer.

A comparison of the Microsoft-specific results presented in this paper with existing academic and government studies on the measurement of price changes for prepackaged software products could be informative. In Table 4, we present a summary of the main findings of the studies of which we are aware.

Direct comparisons of results in these studies to the findings in this paper may be problematic for a number of reasons. First, these studies report results that typically employ data that end in the early to mid-1990s. We have computed results that use MS Sales data beginning in mid-1993 through mid-2001. Since the studies cover different time periods, direct comparisons of results in these studies with the findings in this paper may not be appropriate.

Second, studies of software price indexes published to date have focused primarily on retail level transactions. For Microsoft, sales of full-packaged products sold through the finished goods channel have become an ever smaller and unrepresentative portion of Microsoft's applications sales over time. Instead, volume-related sales now constitute the majority of Microsoft's applications sales. Moreover, OEM sales are not tracked by these studies, and OEM sales are particularly important for desktop operating systems. Therefore comparisons between Microsoft's price changes and those from other studies relying primarily on retail level transactions may not be appropriate. 
Third, most of the U.S. software price index studies published to date, with the exception of that by Oliner and Sichel (1994), employ the hedonic price index method to explicitly adjust for quality changes in software products over time. The matched-model method we have used in this paper attempts to control for quality change by comparing prices only of similar products over time; we have not adjusted the matched-model price indexes further to reflect changes in software product quality over time. However, below we discuss adjustments made by the BEA in part to control for bias in the matched-model method due to failure to incorporate fully quality improvements.

The studies summarized in Table 4 show that prepackaged software prices have been declining over time. Although there are differences between these studies and our analyses, it is worth noting that these declines in software prices (both adjusted and not adjusted for quality change) are largely consistent with the declines in software prices we find using our matchedmodel price indexes.

\section{U.S. Government Producer Price Indexes for Prepackaged Software}

The BLS compiles and publishes a large number of consumer and producer price indexes for different products at varying levels of aggregation. As part of its producer price index coverage, the BLS first began publishing a monthly producer price index for prepackaged software in December 1997. ${ }^{19}$

The BLS prepackaged software price index is based on a survey of producer selling prices, i.e., at the first line of distribution, collected from a sample of manufacturers of prepackaged software (not just Microsoft). The BLS collects price quotes from both the OEM and finished goods channels, and for full versions and upgrades. To preserve continuity in the index, the BLS attempts to collect price quotes for comparable products over time. The current methodology of the index is a fixed basket matched-model Laspeyres price index with plans to update the weights every five to seven years.

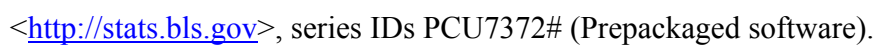


Figure 2 shows the BLS annual aggregate producer price index for prepackaged software, from 1997 through 2001. Given the coverage, scope, and methodology of the BLS producer price index for prepackaged software, comparisons between it and the Microsoft price indexes we describe in this paper can be more meaningful than would be a comparison of the Microsoft matched-model price indexes with those based on the studies cited in Table 4. Over the common 1997 to 2001 time period, the BLS PPI for prepackaged software increased at a rate of 0.35 percent per year, while the price index for the Microsoft Products decreased at a rate of -0.60 percent per year.

\section{Impact of Quality Change and General Inflation}

Although the BLS aggregate PPI for prepackaged software and that for the Microsoft Products show reasonably similar trends, both likely understate quality-adjusted price declines. Specifically, with respect to hedonic price index studies for prepackaged software, the existing literature reports that hedonic quality-adjusted prices for spreadsheets and word processors have generally fallen more rapidly than have the corresponding matched-model price indexes. The latter fail to capture fully many quality improvements between different versions and generations of prepackaged software products over time. ${ }^{20}$

Because of the widely recognized potential understatement of true price declines (or overstatement of true price increases) as measured by matched-model price indexes, in 2000 the U.S. BEA began to make a "bias-adjustment" to the BLS prepackaged software price index. ${ }^{21}$ The adjustment is based on the following calculation: Grimm and Parker (2000) compare two sets of indexes over the 1985 to 1993 period: (1) the Oliner and Sichel (1994) matched-model price indexes for spreadsheets, word processors, and databases; and (2) a BEA hedonic price

Oliner, S. D. and Sichel, D. E. (1994), 'Computers and Output Growth Revisited: How Big is the Puzzle?' Brookings Papers on Economic Activity 2, 273-330.

Grimm, B. and Parker, R. (2000), 'Software Prices and Real Output: Recent Developments at the Bureau of Economic Analysis,' paper presented at the National Bureau of Economic Research Program on Technological Change and Productivity Measurement, Cambridge, MA, March 2000. “.... [a]n annual bias adjustment is made because it is likely - assuming less than complete market equilibrium - that matched-model indexes understate quality-adjusted price declines; quality improvements, such as enhanced power and performance, tend to be introduced in new versions of software, so they are not captured by the matched-model estimates." (p. 15). A further discussion of the BEA's software price estimates is found in Seskin, E. P. (1999), 'Improved Estimates of the National Income and Products Accounts for 1959 to 1998: Results of the Comprehensive Revision,' Survey of Current Business 79, 15-39. 
index for spreadsheets and word processors. ${ }^{22}$ The average annual difference between these two sets of price indexes over the 1985 to 1993 time period is -6.3 percent. The BEA calculates its bias adjustment as one-half of this -6.3 percent annual difference, or -3.15 percent. When compiling and publishing the BEA's quarterly measures of U.S. real gross domestic product and real gross product by industry, the BEA then applies this bias adjustment, converted from annual to quarterly, to the BLS producer price index for prepackaged software.

The use of this adjustment by the BEA to more fully encompass quality-adjusted software price declines than are captured by the BLS matched-model price index suggests that it is reasonable to believe that the matched-model software price indexes computed here for the Microsoft Products also understate quality-adjusted price declines. In addition, the matchedmodel price indexes computed for the Microsoft Products do not take into account changes in the general inflation level (as measured by the GDP implicit price deflator) during the 1993 to 2001

period. Between 1993 and 2001 economy-wide prices rose by an AAGR of approximately 1.90 percent per year as measured by the implicit GDP deflator, which is 6.16 percentage points greater per year than the annual decline in the Microsoft Products of 4.26 percent, based on our matched-model index calculations. ${ }^{23}$ Over the entire 1993 to 2001 time period, the cumulative difference becomes 61.3 percent.

\section{Conclusions}

Although there are differences over time periods and across products, the prices of Microsoft's desktop operating systems and applications have generally been falling over the time period between July 1993 and June 2001. During this time there have been important changes in license arrangements with the growth of volume licensing programs and changes in product form involving a major shift towards sales of Office suites and away from stand-alone sales of Word and Excel. Prices for the Microsoft Products have declined at a rate of 4.26 percent annually.

22 The BEA hedonic price index is an extension of work done by Gandal (1994), Brynjolfsson and Kemerer (1996) and McCahill (1997). 
This compares with an almost two percent rise in economy-wide prices as measured by the implicit GDP price deflator. This decline in the Microsoft Products price indexes likely understates the true price decline, given the improvements in the quality of software products over the 1993 to 2001 time period. Although the research challenges would be considerable, we believe that incorporating quality improvements into the price indexes of these products would result in even greater declines in prices than those reported here.

\section{$\underline{\text { REFERENCES }}$}

Allen, Roy G. D. [1975], Index Numbers in Theory and Practice, Chicago: Aldine Publishing Company.

Balk, B. E. (1995), “Axiomatic Price Index Theory: A Survey,” International Statistical Review 63, pp. 69-93.

Berndt, Ernst R., Susan H. Busch and Richard G. Frank [2001], "Treatment Price Indexes for Acute Phase Major Depression," ch. 12 in David M. Cutler and Ernst R. Berndt, eds., Medical Care Output and Productivity, Studies in Income and Wealth, Vol. 62, Chicago: University of Chicago Press for the National Bureau of Economic Research, pp. 463-505.

Berndt, Ernst R., Robert S. Pindyck and Pierre Azoulay [2003], "Consumption Externalities and Diffusion in Pharmaceutical Markets: Antiulcer Drugs," Journal of Industrial Economics 51, pp. 243-270.

Boskin, M. J., E. R. Dulberger, R. J. Gordon, Z. Griliches and D. W. Jorgenson [1996], Toward a More Accurate Measure of the Cost of Living, Final Report to the U.S. Senate Finance Committee from the Advisory Commission to Study the Consumer Price Index.

Brynjolffson, E. and Kemerer, C.F. (1995), "Network Externalities in Microcomputer Software: An Econometric Analysis of the Spreadsheet Market," Management Science 42, pp. 1627-1647.

Bureau of Labor Statistics (2000), Industry Synopsis, SIC 7372 - Prepackaged Software.

Cocks, D. L. [1974], "The Measurement of Total Factor Productivity for a Large U.S.

$<\underline{\mathrm{http}}$ ://www.bea.doc.gov $>$, Chain-type price index for Gross Domestic Product, Final Sales, and Purchases, published $8 / 2 / 2002$. 
Manufacturing Corporation," Business Economics, 9:7.

Cocks, D. L. [1977], "Drug-Firm Productivity, R\&D, and Public Policy, Pharmaceutical Technology, 1:21,46.

Conference Board [1999], Measuring Prices in a Dynamic Economy: Re-Examining the CPI, New York.

Danzon, P. and L. Chao [2000], "Cross-National Price Differences for Pharmaceuticals: How Large and Why?" Journal of Health Economics, 19: 2, pp. 159-195.

Diewert, W. E. [1992], "Fisher Ideal Output, Input and Productivity Indexes Revisited," Journal of Productivity Analysis 3, pp. 211-248.

Diewert, W. E. [1993], “The Economic Theory of Index Numbers: A Survey,” ch. 7 in W. Erwin Diewert and Alice O. Nakamura, eds., Essays in Index Number Theory, Volume 1, London:

North Holland, pp. 177-221.

Diewert, W. E. (1995), 'Axiomatic and Economic Approaches to Elementary Price Indexes,' Discussion Paper No. 95-01, University of British Columbia.

Gandal, N. (1994), "Hedonic Price Indexes for Spreadsheets and an Empirical Test of Network Externalities," RAND Journal of Economics 25, pp. 160-170.

Gandal, N. (1995), "Competing Compatibility Standards and Network Externalities in the PC Software Market," The Review of Economics and Statistics 77, pp. 599-608.

Grimm, B. and R. Parker [2000], "Software Prices and Real Output: Recent Developments at the Bureau of Economic Analysis," paper presented at the National Bureau of Economic Research Program on Technological Change and Productivity Measurement, Cambridge, MA, March 17, 2000 .

Grohn, A. (n.d.), "Network Effects in PC Software: An Empirical Analysis," unpublished manuscript, Kiel University.

Harhoff, D. and D. Moch (1997), "Price Indexes for PC Database Software and the Value of Code Compatibility," Research Policy 26, pp. 509-520.

McCahill, R. J. (1997), “A Hedonic Study of Prepackaged Software,” Master's Thesis, Virginia Polytechnic Institute and State University.

National Academy of Sciences [2002], At What Price? Conceptualizing and Measuring the Costof-Living and Price Indexes, Panel on Conceptual, Measurement and Other Statistical Issues in Developing Cost-of-Living Indexes, C. Schultze and C. Mackie, eds., Committee on National Statistics, National Research Council. 
Oliner, S. D. and D. E. Sichel [1994], "Computers and Output Growth Revisited: How Big is the Puzzle?” Brookings Papers on Economic Activity, 2, pp. 273-330.

Prud-homme, M. and K. Yu [2002], "A Price Index for (Pre-Packaged) Computer Software Using Scanner Data," draft manuscript, Ottawa: Statistics Canada, Prices Division, July (available from <Marc.Prud'homme@statacan.ca $>$ or $<$ Kam.Yu@statcan.ca $>$ ).

Seskin, E. P. (1999), "Improved Estimates of the National Income and Products Accounts for 1959 to 1998: Results of the Comprehensive Revision," Survey of Current Business 79, pp. $15-$ 39.

Triplett, J. E. (1992), 'Economic Theory of BEA's Alternative Quantity and Price Indexes,' Survey of Current Business 72, pp. 49-52. 
Table 1

Matched-Model Price Indexes
Word (Stand-alone)
Excel (Stand-alone)
Office
Operating Systems

\begin{tabular}{|c|c|c|c|c|c|c|c|c|c|c|c|c|}
\hline Year & Laspeyres & Paasche & Fisher & Laspeyres & Paasche & Fisher & Laspeyres & Paasche & Fisher & Laspeyres & Paasche & Fisher \\
\hline 1993 & 100.00 & 100.00 & 100.00 & 100.00 & 100.00 & 100.00 & 100.00 & 100.00 & 100.00 & 100.00 & 100.00 & 100.00 \\
\hline 1994 & 107.01 & 106.35 & 106.68 & 100.27 & 55.12 & 74.34 & 93.71 & 92.72 & 93.21 & 94.06 & 102.07 & 97.99 \\
\hline 1995 & 99.79 & 99.61 & 99.70 & 159.65 & 59.99 & 97.87 & 79.93 & 78.65 & 79.29 & 89.66 & 98.05 & 93.76 \\
\hline 1996 & 81.11 & 84.23 & 82.66 & 158.53 & 56.44 & 94.59 & 67.14 & 63.50 & 65.29 & 84.73 & 94.74 & 89.60 \\
\hline 1997 & 93.78 & 100.70 & 97.18 & 182.14 & 67.53 & 110.90 & 61.75 & 57.22 & 59.44 & 89.95 & 95.85 & 92.85 \\
\hline 1998 & 92.77 & 110.51 & 101.25 & 184.68 & 65.17 & 109.71 & 64.61 & 58.51 & 61.48 & 91.63 & 96.67 & 94.11 \\
\hline 1999 & 67.36 & 51.35 & 58.81 & 170.20 & 58.72 & 99.97 & 67.14 & 59.13 & 63.01 & 89.33 & 94.06 & 91.66 \\
\hline 2000 & 58.18 & 39.87 & 48.16 & 151.83 & 55.70 & 91.96 & 63.60 & 56.33 & 59.85 & 84.59 & 97.62 & 90.87 \\
\hline 2001 & 59.39 & 41.83 & 49.84 & 150.21 & 54.98 & 90.88 & 71.45 & 63.95 & 67.60 & 90.18 & 104.12 & 96.90 \\
\hline GR: & $-6.3 \%$ & $-10.3 \%$ & $-8.3 \%$ & $5.2 \%$ & $-7.2 \%$ & $-1.2 \%$ & $-4.1 \%$ & $-5.4 \%$ & $-4.8 \%$ & $-1.3 \%$ & $0.5 \%$ & $-0.4 \%$ \\
\hline
\end{tabular}

Notes:

1. The Office price index includes transactions from the "Office," "Office Professional," "Office Pro w/VisFoxPro," "Office Pro/Bookshelf Bundle," "Office w/Bookshelf," "Office Small Business," "Office Pro/Bookshelf/VFoxpro," "Office Premium," "Office Pro w/FrontPage," "Office Pro Special Edition," and "Office Pro w/Publisher" product families.

2. The Microsoft desktop operating systems price index includes transactions from the "MS-DOS," "MS-DOS with Enhanced Tools," "Windows," "Windows for Workgroups," "Windows 95," "WIN95/ISK BUNDLE," "Windows 98," "Windows ME," "Windows NT Workstation," and "Windows 2000 Professional" product families.

Source: MS Sales Data 
Table 2

Matched-Model Price Indexes

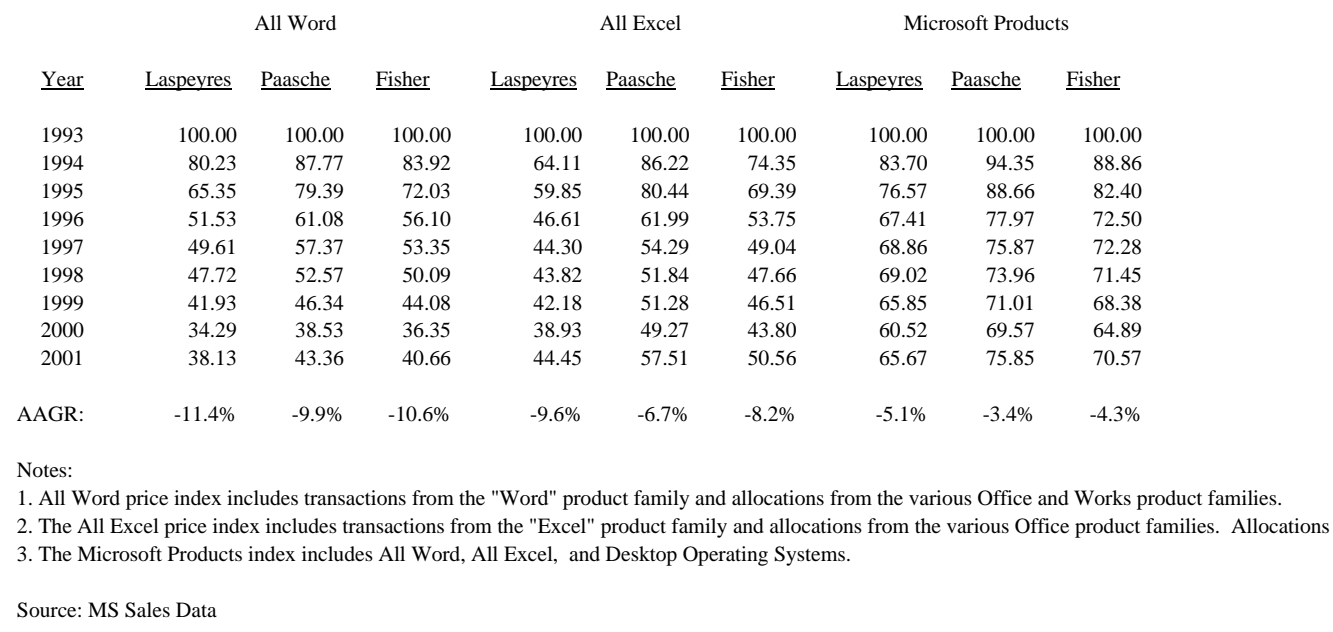


Table 3

Correlation Coefficients between Price and Quantity Relatives

\begin{tabular}{|c|c|c|c|c|c|c|c|}
\hline Year & $\underline{\text { Word (Stand-alone) }}$ & Excel (Stand-alone) & $\underline{\text { Office }}$ & Operating Systems & All Word & All Excel & $\underline{\text { Microsoft Products }}$ \\
\hline '93-'94 & -0.13 & -0.68 & 0.31 & -0.06 & -0.14 & -0.29 & -0.02 \\
\hline '94-'95 & 0.19 & -0.34 & -0.34 & 0.11 & 0.99 & 0.92 & 0.70 \\
\hline '95-'96 & -0.12 & -0.11 & 0.05 & 0.82 & -0.06 & -0.04 & 0.81 \\
\hline '96-'97 & 0.30 & 0.43 & -0.05 & -0.15 & -0.08 & -0.08 & -0.06 \\
\hline '97-'98 & -0.11 & 0.32 & -0.18 & 0.09 & -0.17 & -0.16 & -0.14 \\
\hline '98-'99 & -0.46 & -0.15 & -0.01 & 0.32 & -0.35 & -0.06 & -0.04 \\
\hline '99-'00 & -0.39 & -0.18 & 0.02 & 0.92 & -0.13 & -0.09 & 0.66 \\
\hline '00-'01 & 0.24 & 0.76 & -0.01 & -0.26 & 0.16 & -0.24 & -0.03 \\
\hline Average & -0.06 & 0.01 & -0.03 & 0.22 & 0.03 & 0.00 & 0.24 \\
\hline
\end{tabular}

Source: MS Sales Data 
Table 4

Summary of Price Index Measurement Research

\begin{tabular}{|c|c|c|c|c|c|}
\hline Author(s) & Products Considered & Method Used & Country & Years Covered & Annual Price Change \\
\hline Gandal [1] & Spreadsheets & Hedonic & U.S.A & $1986-1991$ & $-15 \%$ \\
\hline \multirow[t]{2}{*}{ Gandal [2] } & Spreadsheets & Hedonic & 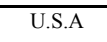 & 1989-1991 & $-4.4 \%$ \\
\hline & Databases & Hedonic & U.S.A & 1989-1991 & $-1.5 \%$ \\
\hline Grohn [3] & Word Processors & Hedonic & Germany & $1985-1995$ & $-11.3 \%$ to $-36.9 \%$ \\
\hline Brynjolfsson and Kemerer [4] & Spreadsheets & Hedonic & U.S.A & 1987-1992 & $-14.8 \%$ to $-16.5 \%$ \\
\hline \multirow[t]{2}{*}{\begin{tabular}{|l|} 
McCahill [5] \\
\end{tabular}} & Spreadsheets & Hedonic & U.S.A & 1986-1993 & $-9.0 \%$ to $-16.9 \%$ \\
\hline & Word Processors & Hedonic & U.S.A & 1985-1994 & $-15.1 \%$ to $-18.5 \%$ \\
\hline \multirow[t]{2}{*}{ Harhoff and Moch [6] } & Databases & Hedonic & Germany & $\begin{array}{l}1986-1994 \\
\end{array}$ & $-7.41 \%$ \\
\hline & Databases & Matched-model & Germany & $\begin{array}{l}1986-1994 \\
\end{array}$ & $-9.25 \%$ \\
\hline \multirow[t]{3}{*}{ Oliner and Sichel [7] } & Word Processors & Matched-model & U.S.A & 1985-1993 & $-2.6 \%$ \\
\hline & Spreadsheets & Matched-model & U.S.A & 1985-1993 & $-4.5 \%$ \\
\hline & Databases & Matched-model & U.S.A & 1985-1993 & $-4.7 \%$ \\
\hline BLS[8] & General & Matched-model & U.S.A & 1997-2002 & $-0.45 \%$ \\
\hline Grimm and Parker [9] & General & Interpolation, Matched-model, and Hedonic & U.S.A & $1959-1998$ & $-10.9 \%$ \\
\hline Prud'homme and $\mathrm{Yu}[10]$ & General & Matched-model & Canada & $1996-2000$ & $-4.4 \%$ to $-7.9 \%$ \\
\hline
\end{tabular}

Sources:

1. Gandal, N. (1994), 'Hedonic Price Indexes for Spreadsheets and an Empirical Test of Network Externalities,'RAND Journal of Economics 25, 160-170.

2. Gandal, N. (1995), 'Competing Compatibility Standards and Network Externalities in the PC Software Market,'The Review of Economics and Statistics 77, 599-608.

3. Grohn, A. (n.d.), 'Network Effects in PC Software: An Empirical Analysis,' unpublished manuscript, Kiel University.

4. Brynjolffson, E. and Kemerer, C.F.(1995), 'Network Externalities in Microcomputer Software: An Econometric Analysis of the Spreadsheet Market,'

Management Science 42, 1627-1647.

5. McCahill, R. J. (1997), “A Hedonic Study of Prepackaged Software,” Master's Thesis, Virginia Polytechnic Institute and State University.

6. Harhoff, D. and Moch, D. (1997), 'Price Indexes for PC Database Software and the Value of Code Compatibility,'Research Policy 26, 509-520.

7. Oliner, S.D. and Sichel, D.E. (1994), 'Computers and Output Growth Revisited: How Big is the Puzzle?' Brookings Papers on Economic Activity 2, 273-330.

8. http://stats.bls.gov.

9. Grimm, B. and Parker, R. (2000), 'Software Prices and Real Output: Recent Developments at the Bureau of Economic Analysis,'paper presented

at the National Bureau of Economic Research Program on Technological Change and Productivity Measurement Cambridge, Massachusetts, March 17, 2000.

10. Prud'homme, M. and Yu, K. (2002), 'A Price Index for Computer Software Using Scanner Data,' paper presented at The Brookings Workshop on Economic Measurement, May 2003. 


\section{Figure 1}

\section{Matched-model Price Indexes:Desktop Operating Systems}

1993 - 2001

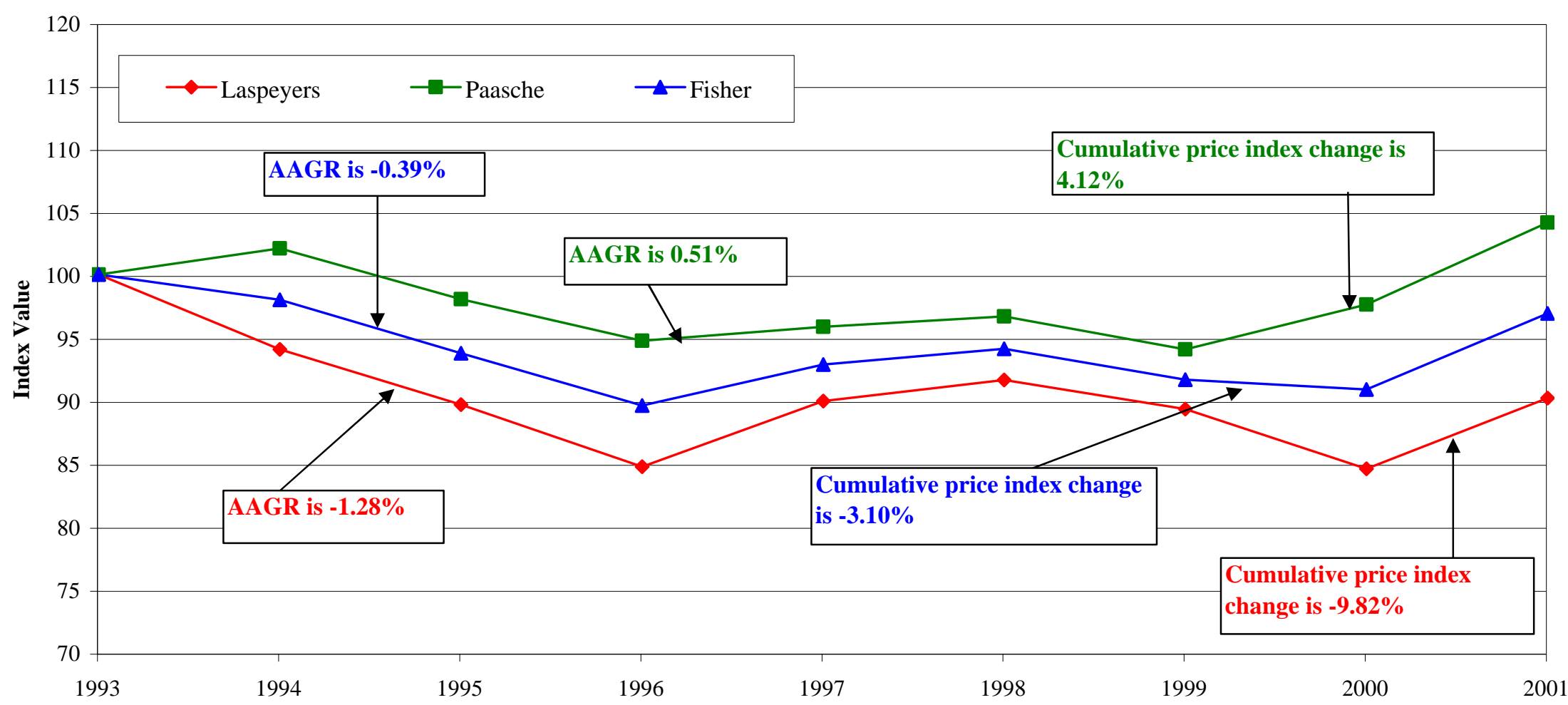

Notes:

1. The desktop operating systems index includes transactions from the "MS-DOS," "MS-DOS with Enhanced Tools," "Windows," "Windows for Workgroups," "Windows 95," "WIN95/ISK BUNDLE," "Windows 98," "Windows ME," "Windows NT Workstation," and "Windows 2000 Professional" product families.

2. For a price series starting in year 0 and ending in year $n, A A G R=\left(P_{n} / P_{0}\right)^{1 / n}-1$.

Source:

MS Sales Microsoft "As Shipped" Perspective, July 1993 - June 2001. 
Figure 2

BLS and MS Sales Price Indexes Comparison

1997 - 2001

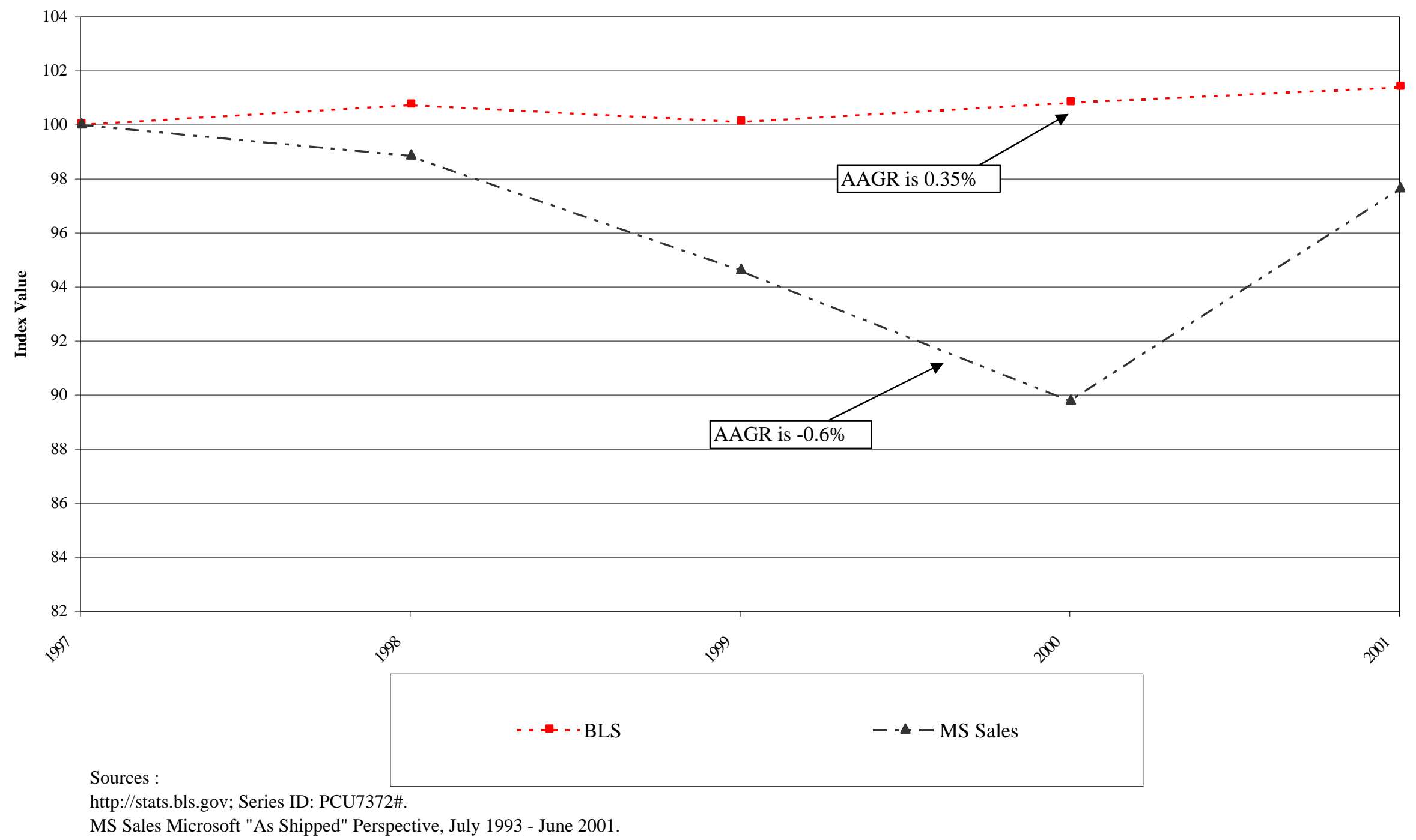

